\title{
EL PROTAGONISMO DE LA MUJER REPRESENTADO POR ARTISTAS DESDE LA VANGUARDIA HASTA NUESTROS DÍAS ${ }^{1}$
}

\author{
Natalia Plaza Morales ${ }^{2}$
}

\begin{abstract}
El protagonismo de la mujer representado por artistas desde la vanguardia hasta nuestros Resumen: En el siguiente trabajo repasamos el arte de algunas autoras que han trabajado con la posición femenina a través del cuerpo desde la vanguardia hasta la actualidad. Nuestro objetivo es interrogarnos acerca de cómo el dispositivo del cuerpo ha ido transformándose como espacio de experimentación que ha permitido a la artista romper barreras, innovar e indagar en una serie de usos, prácticas y emociones hasta entonces desconocidas. La influencia de algunos movimientos de vanguardia, así como la de Duchamp como figura predecesora del arte conceptual, han permitido a la artista reinventar y deconstruir la identidad femenina a través del arte.

Palabras clave: Cuerpo, vanguardia, mujer, arte, transformación.
\end{abstract}

The Role Played by Women in Female Artistic Productions from the Avant-Garde to the Present

Abstract: In the following work we conducted a review of the art of some authors who have worked with the body and the female position from the avant-garde to the present. Our objective is to ask ourselves about how the device of the woman's body has been transformed as a feminine experimentation space that has allowed the artist to break barriers, innovate and investigate a series of uses, practices and emotions that are manifested through her body. The influences of some avant-garde movements and artists such as Duchamp and conceptual art, have allowed female artists to reinvent and deconstruct female identity through art.

Key words: Body, vanguard, woman, art, transformation.

\section{Los movimientos vanguardistas y la posición femenina}

En los años 50-60 la mujer seguía perpetuando su rol tradicional, de manera que, en materia artística, eran muchos los catálogos y modelos publicitarios que dibujaban a la mujer en su papel de ama del hogar, de cuidadora de hijos y de esposa. Sin embargo,

\footnotetext{
${ }^{1}$ Fecha de recepción: 17/03/2019.

${ }^{2}$ Profesora Asociada de Lengua Española en el Instituto de Educación Superior IESEG School of Management; $\bowtie$ n.plaza-morales@ieseg.fr.
} 
a partir de los finales de los 60 y durante la década de los 70, los movimientos feministas irían mermando en las conciencias y en la sociedad española. Estos ya habían comenzado a tomar visibilidad en Francia y en Inglaterra. La industrialización y la consecuente incorporación de la mujer al mundo laboral serían factores que ayudarían a la transformación de la mujer; dicha evolución coincidirá con un cambio artístico caracterizado por su tono experimentalista y liberador.

Las vanguardias históricas contribuyeron a una revolución del papel femenino tanto en las artes visuales y en la literatura como en la cotidianidad misma. A partir de entonces, algunas artistas pioneras de estos movimientos van a valerse del cuerpo femenino como símbolo de una identidad en transformación. La idea fundamental consiste en desdibujar algunos parámetros de representación y de percepción del cuerpo de mujer y "subvertir la imagen sublimada de belleza, perfección y armonía que les había sido impuesta a lo largo de los siglos y hacer visible su dolor, sus sentimientos, su realidad” (Rodríguez Barbero 2015: 26). En cierto sentido, el cuerpo pasa a convertirse a nivel artístico en un emblema de reivindicación social y cultural. Se trataría de desubicar a la mujer de su relación al cuerpo tradicional y de su lectura biológica-sexual e interpretar su propio cuerpo como un medio reivindicativo.

El cuerpo aparecerá convertido en lugar de experimentación y de subversión para deconstruir el género normativo. De esta forma, a través del arte de algunas de estas autoras, podríamos pensar que estaríamos ya ante la puesta en marcha, por medio de la imagen, de ideas predecesoras a los conceptos de performatividad, los cuales serían más tarde desarrollados por teóricas queers como Judith Butler (1990). Recordemos que, para Butler, el género es performativo, una argumentación que la filósofa interpreta con el sentido de que somos hombres o mujeres no con respecto a nuestra diferencia sexual sino que esta diferenciación es consecuencia de nuestra cultura. Para la filósofa, los 
actos performativos del género se convierten en rituales que realizamos de manera repetitiva, pero que responderían a una intencionalidad puesta en marcha por las estructuras sociales: "La performatividad no es un acto único, sino una repetición y un ritual que logra su efecto mediante su naturalización en el contexto de un cuerpo, entendido, hasta cierto punto, como una duración temporal sostenida culturalmente" (Butler 1990: 15).

Algunas figuras femeninas cercanas al movimiento artístico surrealista que nos resultan interesantes para nuestro análisis serían las pintoras Frida Kahlo y Maruja Mallo. Esta última es poco conocida a nivel internacional, a pesar de ser considerada por la crítica de la historia del arte como una de las precursoras claves de la corriente surrealista. Sin entrar en la descripción de los supuestos teóricos del surrealismo, podemos decir que este movimiento trajo consigo, además de una posición transcendental con respecto a la muerte, una intención de disolver las contradicciones y las formas de pensamiento del lenguaje humano. Éstas han sido habitualmente representadas y clasificadas de manera binaria, de ahí que la figuración de la mujer también se haya desdibujado con referencia a sus connotaciones opuestas y negativas con respecto al hombre.

En este sentido, en su Posición política del surrealismo (1935), Breton afirma que la aspiración que tienen los artistas modernos para construir un mundo nuevo no debe limitarse a la expresión de una forma particular, como por ejemplo, el sentido ideológico o político. El artista tampoco puede restringir su ambición a la manifestación de una emoción, por violenta y profunda que pueda llegar a ser. De tal forma que, para el surrealista francés, tanto la emoción singular como la idea particular carecerían de transcendencia si la obra no reflejase más que una de estas particularidades. Teniendo en cuenta estas premisas, y en lo que respecta a la obra de Frida Kahlo, ésta ha sido 
analizada por su carácter híbrido, interpretándose mayoritariamente como símbolo representativo de un espacio íntimo y personal muy cercano a la estética del Unheimlich freudiano. Podríamos sugerir que la esencia feminista de algunos de sus cuadros se presenta como voz (el género que ya no responde a los parámetros tradicionales) e imagen (la feminidad) que la artista potencia de una forma muy singular. Si tenemos en cuenta que la mujer latinoamericana se encontraba ausente del panorama artístico, su discurso aparece como la voz que no sólo lucha contra su imagen canónica (la mujer sensible, la belleza sublime, la sonrisa angelical de la mujer...) sino que su fuerza se ve potenciada gracias a una exhibición que le permite manifestarse ante una sociedad que la invisibilizaba. ¿Cómo desprenderse entonces de su condición de oprimida, de marginada y de opuesta al sistema patriarcal? Este discurso transgresivo al que nos lleva Frida se leería gracias a su propia figuración femenina.

Esto es algo que subraya Sofía Reyes Sepúlveda (2009), al comparar el arte representativo y transformador de Frida Kahlo con otras artistas vanguardistas que, sin embargo, no han sabido posicionar a la mujer con un ideal propio. A través del arte de estas autoras, la mujer seguiría apareciendo ante los ojos del espectador de dos maneras. O, por un lado, como un objeto de deseo del imaginario masculino o, por el otro, permanecería ausente. La falta de visibilidad se justificaría para evitar confrontar su arte al imaginario femenino, todo ello con la intención de no reflejarse en el canon occidental dominante que las limitaba (Reyes Sepúlveda 13: 2009).

En los autorretratos de Frida Khalo, la artista aparece representada de forma natural, son sus gestos los que nos delatan que el rostro femenino ha sufrido un cambio, una transformación en la manera con que la mujer se representa y se percibe a sí misma. Como si se posicionase ante un espejo, la artista mira al espectador desafiante, con un gesto pensativo, al tiempo que orgulloso. Parecería que Frida es consciente de su 
situación desdichada, pero se enfrenta a su presente sin miedos, sin vacilaciones. El malestar que le rodea nos lo muestran los decorativos pintados alrededor de su busto: el gato negro de la mala suerte en su hombro izquierdo, y, en el derecho, el mono. Este animal simboliza al hombre, más concretamente a su marido, el célebre pintor muralista Diego Rivera, con el que atraviesa una gran crisis matrimonial en el momento en que realiza tal obra. El espectador observa a una mujer que no deja entrever la sensibilidad tradicional asociada al género femenino. Intuimos que, a pesar del sufrimiento, la imagen que ha querido transmitir la artista mexicana es la de una mujer que sabe guardar el temple y que no se deja llevar por el sentimentalismo ante su destino. A su vez, esta mujer no se adecúa a los cánones de belleza ni persigue amoldarlos. Frida consigue un aspecto natural y resalta algunos trazos como sus cejas espesas y unidas, con vello en el mentón y en los labios superiores. Y más que ver tales rasgos como la búsqueda de una masculinización femenina o de la representación de un ser próximo a la androginia, tal y como algunos críticos la reclaman, podríamos pensarla como manera de desnaturalizar la imagen femenina.

La figuración de la mujer sería aquella de un ser fuerte que puede poseer rasgos físicos como el hombre, características que a menudo habría escondido para potencializar su feminización y diferenciarse de éste. Ante tales sugerencias, la mujer deja de ser un mero objeto de deseo y de contemplación masculina. Saldrían a relucir otros aspectos de su personalidad que a menudo permanecerían ocultos bajo la cualidad de la belleza canónica como rasgo primordial para resaltar en la mujer. Así pues, los autorretratos de Frida desestabilizarían el canon occidental de una manera natural y poco excesiva: 
Dicha proyección del deseo masculino es lo que ponen en jaque los retratos de mujeres realizados por Frida Kahlo: no son representaciones de mujeres deseables sexualmente ni tampoco son fáciles de comprender. Son imágenes que escapan al imaginario occidental europeo. (Reyes Sepúlveda 2009: 16)

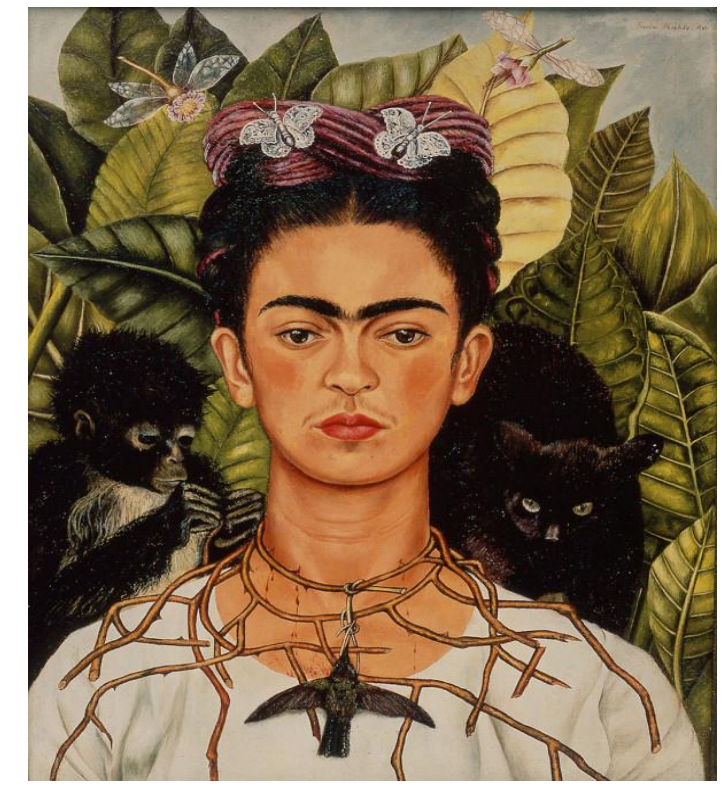

Gráfica 1. Frida Kahlo. Autorretrato con mono (1943)

Cuando vemos algunas obras de Frida y las comparamos con la serie Cabeza de mujer (1941) de la pintora española Maruja Mallo, adivinamos un gesto similar al del autorretrato de Frida. En el cuadro de la artista de Lugo, la imagen de mujer muestra un gesto duro, desafiante, casi malvado. Un retrato completamente distorsionado de los cánones de belleza de mujer dulce y angelical, un rostro nada sonriente, pero, a su vez, con mucho carácter y personalidad. 


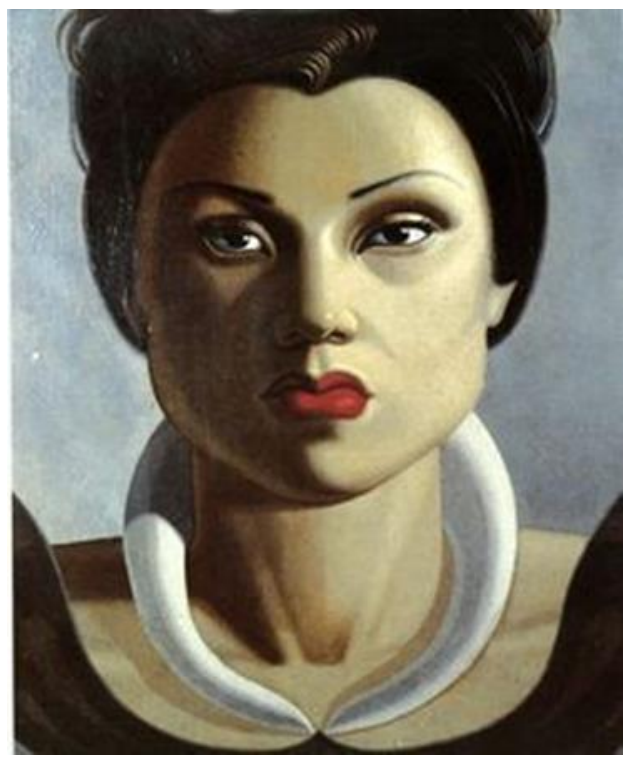

Gráfica 2. Maruja Mallo.Cabeza de mujer (1941)

Al mirar esta imagen de Maruja Mallo, podríamos incluso pensar, tras una primera visualización, en el rostro de la madrastra de Blancanieves, por lo que reforzaríamos la idea, según la cual, estamos acostumbrados a concebir a la mujer entre uno de los dos polos que la han caracterizado: o aquel de malvada, de bruja (con aire enfadado y rasgos fuertes), o el de inocente y angelical, un rostro virginal como el de una niña. Mallo nos presenta a una mujer bella pero que deja de apreciarse como un ser dulce e inocente. Para ello, ésta deja de sonreír y ofrece un rostro duro. Esta ruptura de comportamiento y maneras del imaginario de mujer nos llevaría a recordar el contexto histórico en el que la pintora de la generación del 27 vivió y expresó su arte. Conocida por su personalidad extravagante y su vida aventurera, Mallo fue, como nos cuenta Estrella de Diego, una artista que se pudo codear con las grandes figuras artísticas y literarias del surrealismo y de la vanguardia: Salvador Dalí, Miguel Hernández, Rafael Alberti y Pablo Neruda, entre otras grandes figuras que la admiraron por la 
meticulosidad de su arte, sus colores y sus figuraciones. Formó parte de aquellos artistas que tuvieron que exiliarse tras la Segunda República con la llegada de la dictadura franquista. $\mathrm{Y}$ al igual que otras compañeras artistas, como por ejemplo, la escritora madrileña Luisa Carnés, también Mallo pagó con el olvido y el exilio, a pesar de su genialidad. Ser mujer y artista eran dos categorías poco visibles para el régimen, y a pesar de que todas las ideas prometedoras de la Segunda República habían supuesto un suspiro esperanzador para la mujer moderna, aquellos ideales se congelaron y se abanderaron de nuevo con los valores tradicionales. Así, como lo cuenta José Luis Ferris (2004) en su biografía de Maruja Mallo (pseudónimo de Ana María Gómez González), la artista supo adaptarse al exilio y siguió disfrutando, aunque con escasa proyección y visibilidad, de la vida intelectual en Chile y Argentina. Regresó a España en 1961, un país con el que siempre mantuvo fuertes vínculos. Y, como nos relata Ferris, no será hasta la muerte de Franco y durante la movida madrileña, cuando el nombre de Maruja Mallo resuene con fuerza en tanto que figura emblemática de libertad y transgresión.

\section{El arte conceptual y la reivindicación femenina}

El arte conceptual fue originado por el francés Marcel Duchamp en los años 70, quien, acompañado de sus famosos ready-mades, pretendió privilegiar la idea, la imagen mental, por encima de la representación artística. En este sentido, el valor de lo visual perdía importancia con respecto a lo que se podía pensar o decir sobre una obra artística. A partir de aquí, el arte comenzó a descifrarse como un precursor de discursos con fuerte potencial social o político. El artista, ayudado por el espectador mismo, se 
convertía en un transmisor clave de los cambios y preocupaciones de su tiempo. Las múltiples interpretaciones, a las que nos llevaba el arte de Duchamp y de sus futuros discípulos, nos permitían constatar una ruptura clave con la tradición artística. Dichas lecturas presagiaban que la sociedad contemporánea se valdría de esta nueva funcionalidad artística para cambiar el horizonte estético-social del arte internacional. Así pues, la clave para entender el arte conceptual estaría en la forma en que miramos la obra. Ésta no se contemplaría a nivel de la retina, como lo afirma el propio Duchamp, sino que lo haría a un nivel superior de entendimiento:

No es la cuestión visual del ready-made lo que cuenta, sino el hecho de existir mismo. No hay necesidad de mirarlo para entrar en el dominio de los ready-mades. ¿Entendéis lo que quiero decir? Ya no es una cuestión de visualidad. La obra de arte ya no es visible, por decirlo de alguna manera. Es completamente gris. Ya no es retiniana. ${ }^{3}$

En nuestra actualidad, admitimos que el ready-made de Duchamp ha sido un concepto clave que ha marcado el arte, la escritura y el sector comercial, puesto que ha reinvertido los cánones como un gesto artístico que se ríe del arte mismo, y al mismo tiempo, nos hace pensar más allá del concepto. El ready-made, como lo declara Graciela Speranza, ha revolucionado el arte y el pensamiento, pero esto a su vez le ha valido una enorme crítica:

De un lado y del otro del Atlántico, es evidente, la obra de Duchamp ha marcado la historia del arte del siglo y su nombre emerge como única fuente de unidad por detrás de la aparente heterogeneidad de prácticas estéticas que corresponden a nombres diversos: neodadá, nuevo realismo, pop art, assemblage, happenings, arte conceptual, crítica institucional, post producción. Su legado se resiste a una descripción totalizadora y una evaluación unívoca, pero la potencia de un

\footnotetext{
${ }^{3}$ La traducción es nuestra. Entrevista con Marcel Duchamp, (Neyens 1965). "Will go underground". Entrevista publicada por Tout-fait, the Marcel Duchamp Studies. Online Journal, 2002.
} 
incontestable "efecto Duchamp" recorre el arte de las últimas décadas (Speranza 2013: 21).

En cuanto a los referentes femeninos del arte conceptual, podríamos mencionar a Ana Mendieta, una artista de origen cubano emigrada a los Estados Unidos, quien cultivó tanto la pintura como la escultura y las performances, a través de géneros como el Body-art y el Landscape. Su obra, cercana a la de otros artistas vanguardistas como Hans Bellmer, nos transmite sensaciones extremas, violentas e inusitadas. Algunas de sus pinturas y performances sobrepasan los límites de lo sexual y de la identidad. Fue una artista comprometida con el feminismo y con las desigualdades raciales. La sangre y la violencia se convirtieron en elementos claves de su obra, quizá con la esperanza de suscitar en el espectador una reacción ante todos aquellos hechos que le preocupaban más allá de la indiferencia social que los marcaba. La violación, la identidad racial, lo salvaje... todos estos temas tratados en sus obras poseían un hilo conductor, el cuerpo, que permitía desestabilizar al espectador, quien se confrontaba a la violencia simbólica mediante el despertar inmediato de sus pulsiones de muerte. Parecería que, tal equilibrio entre las pulsiones de vida y muerte de las que nos hablaba Freud en Más allá del principio de placer (1920), se desataba en el arte de Ana Mendieta como una ventana volcada hacia los instintos mortíferos del ser humano. En este sentido, Freud declaraba:

Hay como un ritmo titubeante en la vida de los organismos; uno de los grupos pulsionales se lanza, impetuoso, hacia adelante, para alcanzar lo más rápido posible la meta final de la vida; el otro, llegado a cierto lugar de este camino, se lanza hacia atrás para volver a retomarlo desde cierto punto y así prolongar la duración del trayecto. (Freud 1920-22: 22) 


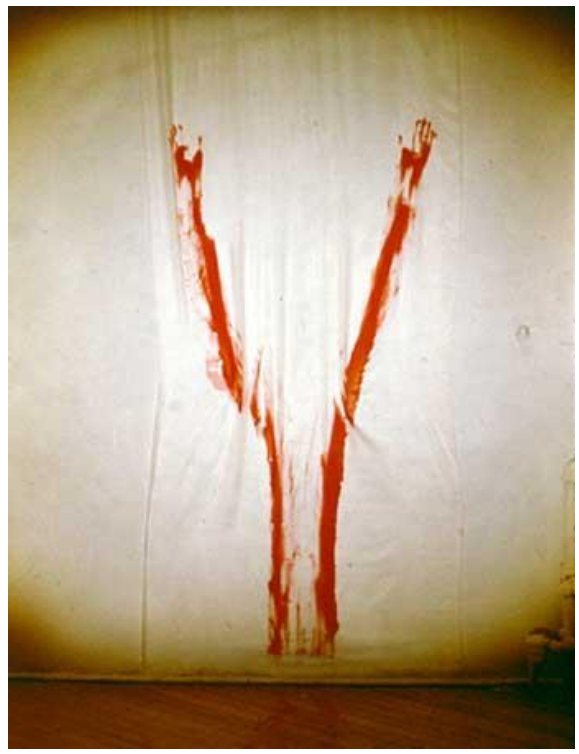

Gráfica 3. Ana Mendieta. Body tracks (sin título)

En la obra de Mendieta observamos cómo la tierra se convierte en un escenario habitual para experimentar con la vida (la naturaleza) y con la muerte (el cuerpo):

A través de sus performance, Mendieta deja marcado siluetas de su cuerpo en la tierra, esto como representación de la conexión de la artista con el vientre materno, las siluetas son la representación de ella y la naturaleza es el útero, además de la fuerza femenina que tanto defendió. (Carpio Jiménez et al 2014: 5)

Con respecto al género del Pop Art, éste manifestó el deseo de reinvertir, balancear y subvertir los patrones culturales, sociales y de género convencionales. Se trataba de un arte popular, focalizado en lo cotidiano, y contrario al expresionismo abstracto. Tanto Andy Wahrol como Duchamp sucumbieron a inmortalizar su alter-ego femenino como parte de su obra y como juego de identidad. Pero, a pesar de sus ideas prometedoras para desestabilizar el género, y tal y como lo declara Grace Morales, el pop art fue un arte protagonizado por hombres, ajeno y distante a la opresión y a la 
desigualdad femenina. Sin embargo, constituyó el punto de partida que sirvió a algunas artistas femeninas para denunciar su posición de objetivización y de sumisión sexual y política al patriarcado:

Las artistas del pop art fueron las más combativas políticamente, porque utilizaron los medios y códigos de la sociedad de masas para denunciar de forma explícita la sumisión y el proceso de objetivación de la mujer en el siglo XX, frente a otros nombres (masculinos) que jugaron de forma más sinuosa en este terreno, con el distanciamiento, la ironía y la confusión. (Morales 2018: s/ n)

Así pues, el Pop art fomentó el camino para que la artista pudiese autorepresentarse de una forma habitual desde las facetas que la habían caracterizado tradicionalmente hasta aquellas formas y estilos corporales que querría cambiar y resaltar. La estadounidense Cindy Sherman es quizás una de las artistas internacionales inspiradas del pop art que mejor ha sabido retratarse como mujer para denunciar la identidad femenina tradicional como aquella asociada a la cosificación. En una de sus fotografías que servirá para la campaña de Mac, Sherman se retrata como una mujer repleta de maquillaje y con peinado perfecto. Dicha imagen representa el rol femenino de mujeres adineradas, esposas de hombres de gran estatus social, cuya preocupación es aquella de mantenerse bellas y de cuidar del hogar. Con esta performance, la artista denuncia el miedo absurdo de la mujer moderna a envejecer, lo que la conduciría a operaciones estéticas y a un exceso de maquillaje para esconder su verdadero yo y el paso del tiempo en su cuerpo. 


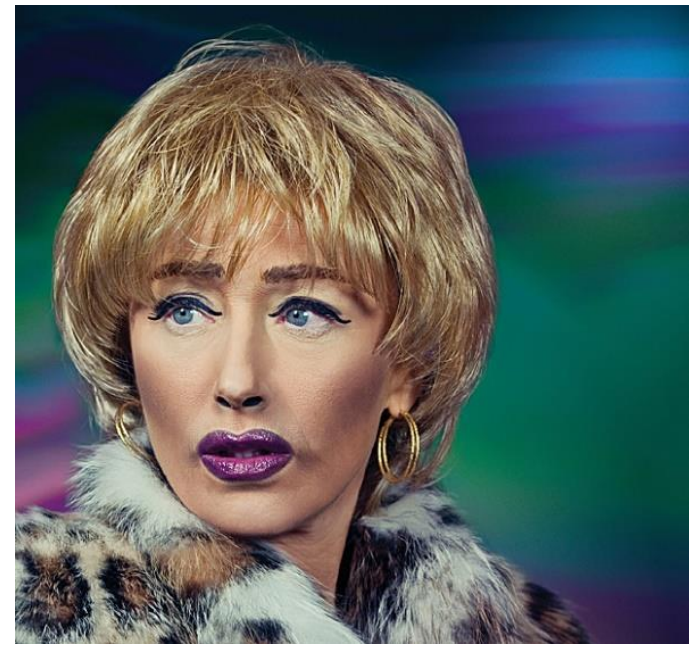

Gráfica 4. Cindy Sherman. Sin título (2010-2012)

En su blog "A la sombra de los deseos en flor", la escritora mexicana, Ana Clavel, nos habla de cómo la artista norteamericana ha sabido parodiar los roles de género a lo largo de su carrera artística, empleando para ello una estética singular, burlona y extravagante: "Con un arsenal de disfraces, maquillajes, prótesis, escenografías Sherman juega con esas otras encarnaciones posibles como si se tratara de un gran carnaval, donde lo grotesco y lo paródico suelen confundirse" (Clavel, 2013: s/n). La obra de Sherman evoluciona hacia una estética bellmeriana, de manera que la artista americana recurre a cuerpos femeninos desarticulados, mutilados. En este sentido, se acerca en algunas de sus obras a un estado violento y macabro, cada vez más parecido al de Mendieta, que deja presagiar que existe también un deseo de sacar a relucir los instintos más primarios del ser humano. Vidal Claramonte desarrolla sus propósitos:

Su obra parece cada vez más preocupada por la violencia contemporánea en general y por lo que se ejerce sobre el cuerpo femenino en particular: así, a finales del siglo $\mathrm{XX}$ produce imágenes traumáticas en blanco y negro de desmembramientos y violaciones, usando muñecas que representan a la mujer como objeto sexual torturado, violentado, mutilado y manipulado. (Vidal Claramonte 2013:52) 
Otras autoras vanguardistas del pop art se concentran más en objetos triviales para denunciar o dar cuenta de sus inquietudes. Mari Chordà es una artista catalana que desarrolla su arte a partir de los años 70, representado en algunas colecciones la sexualidad femenina a través de un objeto colorista, asimétrico e indefinido. En las imágenes de su colección, Vaginals, observamos el órgano genital femenino como un paisaje de expresión visual que nos trasmite una sensación alegre y optimista.

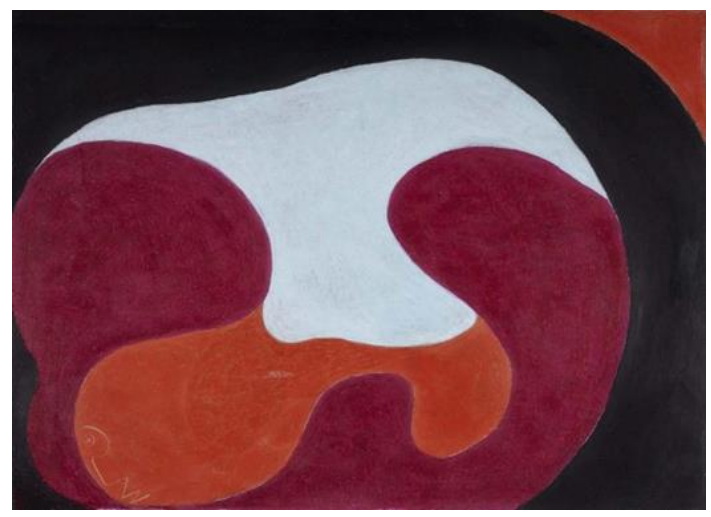

Gráfica 5. Mari Chordà. Vaginals, 1966.

Elena del Rivero es una artista muy cercana al arte de Duchamp, quien explora, entre otros temas, lo "femenino", de una forma casi mística y espiritual. En una de sus obras recientes, Les amoureuses (Elena y Rose), la artista valenciana aparece junto a la fotografía de Duchamp jugando al ajedrez y tejiendo un collar de perlas. Recordemos que, en la fotografía inicial de 1963, el artista francés se encontraba junto a una mujer desnuda con quien jugaba tranquilamente al ajedrez. Esta obra se leería como un homenaje al arte de Duchamp y al juego entre la idea y la representación misma. El significado de la mujer que teje nos recuerda a la historia de Penélope esperando la 
vuelta de Ulises, pero, en este caso, la artista se coloca junto a Duchamp, al mismo nivel, aunque en épocas distintas y sin ánimo de esperar a nadie. La perla es un elemento ya utilizado en otras de sus obras, tal es el caso de las "Cartas a una madre". Y, como lo afirma el catálogo de la Col-lecció d'Art i Punt d'Investigació "La Relació", Duoda, esta joya evoca lo "femenino libre", como clave de una feminidad que brilla por su carácter autónomo.

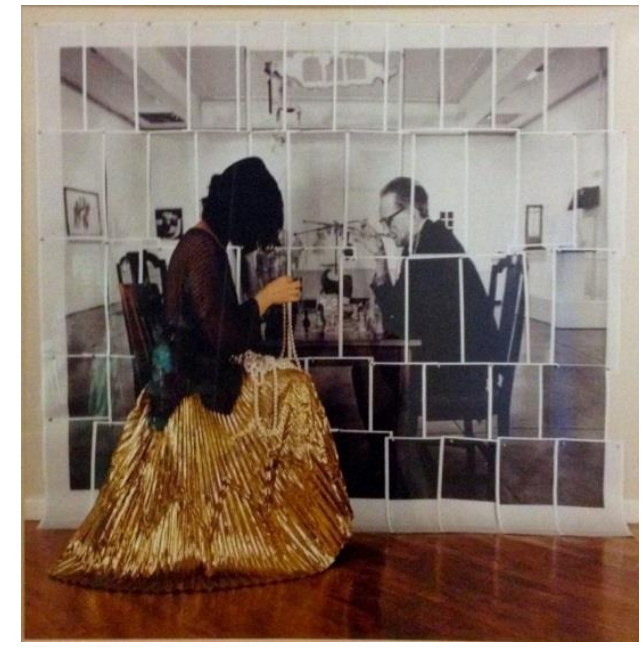

Gráfica 6. Elena del Rivero. Les amoreuses (Elena y Rose), 2001.

Esther Ferrer es sin duda una de las grandes activistas de la lucha feminista que ha sabido reivindicar la igualdad a través de la expresión con su propio cuerpo. Un discurso que pretende denunciar la cultura patriarcal al mostrar al espectador que la mujer es libre de utilizar su cuerpo como le precie, y, sobre todo, al ofrecer una mirada singular, propia y renovada de sí misma. Algunas autoras como Ferrer han sabido conquistar un lugar para el cuerpo femenino, un espacio que había sido explotado siempre como vacío y contemplativo. Esto es algo que subraya Marisa Vadillo al hablar de la perspectiva tradicional del cuerpo femenino con respecto al arte. Para Marisa 
Vadillo, la obra de Ferrer, al igual que la de Kahlo y Mendieta, se caracterizarían por el vínculo con la naturaleza, aunque, en el caso de Ferrer, esta integraría elementos artificiales para recrear los componentes naturales del cuerpo femenino. Quizás esta pretensión de Ferrer al combinar lo natural y lo artificial supone una transgresión con respecto a nuestro presente histórico, donde lo artificial precede y sustituye en muchas ocasiones a lo natural. En este sentido, no podemos obviar El Manifiesto Ciborg de Haraway (1984) como una teoría clave para entender las relaciones sociales entre el feminismo y la era tecnológica: "Las máquinas de este fin de siglo han convertido en algo ambiguo la diferencia entre lo natural y lo artificial, entre el cuerpo y la mente, entre el desarrollo personal y el planeado desde el exterior y otras muchas distinciones que solían aplicarse a los organismos y a las máquinas" (Haraway, 1984: 5). El ciberfeminismo, como lo detalla García Manso, nos lleva a un intento de convivir más allá de la identidad femenina, a pensarnos cuerpos-máquinas que rompen con las dicotomías tradicionales.

Según la propia Ferrer, ella siempre ha expresado su arte tal y como le ha gustado hacerlo, con total libertad, aunque ello haya podido conllevar la burla o la incomprensión de algunos sectores del público y de la crítica. Ferrer se ha valido de la performance como una forma de expresión privilegiada para actuar conjuntamente con el espectador, quien construiría también la obra con su propia reacción y acción ante lo visto. Dicha libertad parece acompañar su percepción de la sexualidad femenina con su performance "Íntimo y personal", con la cual se opone al falocentrismo en tanto que poder masculino privilegiado sobre el cuerpo femenino. El cuerpo de mujer termina ocupando un lugar propio, aquel que la mujer misma le pretenda y le quiera dar. El desnudo, la exhibición del cuerpo, son bienvenidos, siempre y cuando sea la mujer la que rija las pautas con su cuerpo y la manera en que éste debe interactuar, entre aquello 
que quiere mostrar y hacer entender al otro, en este caso, a la mirada masculina dominante.

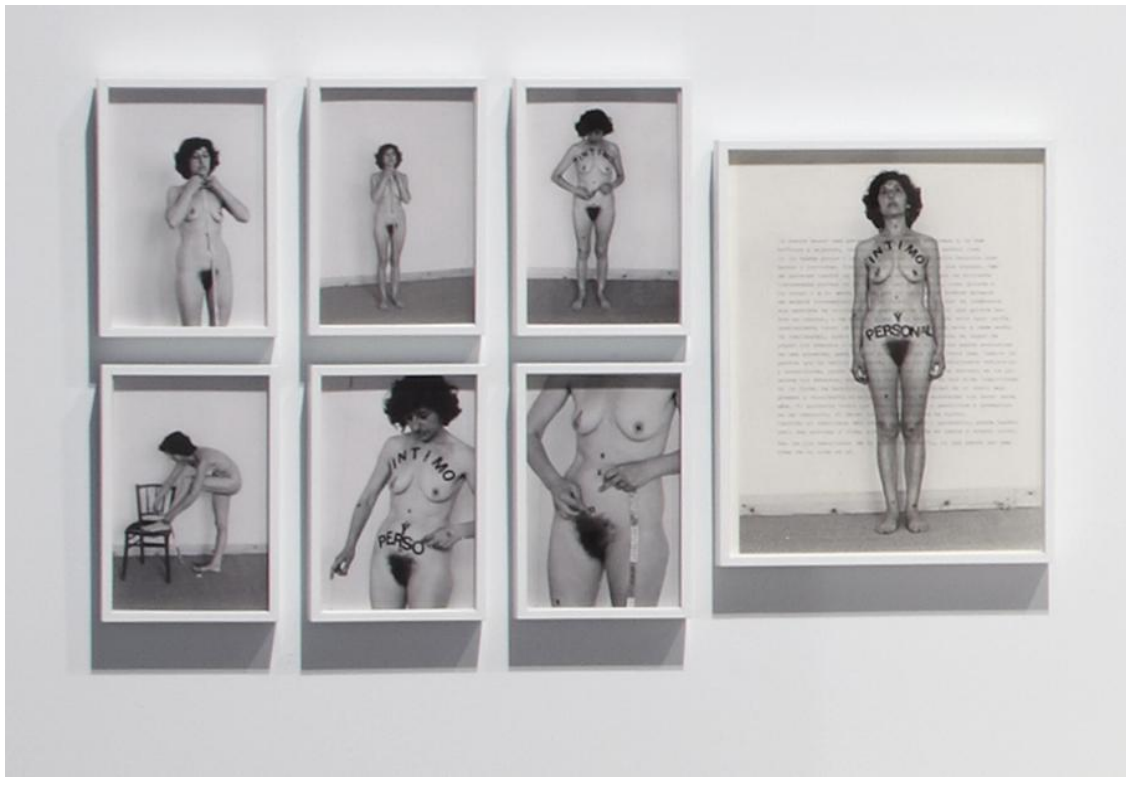

Gráfica 7. Esther Ferrer. Íntima y personal (1977)

Es interesante recordar que la serie "Íntima y personal" de Ferrer coincide con las teorizaciones feministas sobre el placer visual en otros dominios artísticos como el cine. Así, Visual Pleasure and Narrative Cinema (1975), de Laura Mulvey, cuestionaba precisamente cómo el discurso falogocéntrico ha perpetuado a la mujer en su papel de objeto y reafirmado el poder masculino para así afianzar una identidad femenina a través de su propio deseo. Para Esther Ferrer, y como lo declara en varias ocasiones, lo importante es marcar un lugar, una forma de sentirse con y en el mundo. Todo lo que la artista busca es una forma singular de enfrentarse a sus propios pensamientos y de convertirlos en arte. Los objetos cotidianos (cuchillos, sillas...) le ayudan a exhibir 
pensamientos, ideas abiertas, las cuales permiten al espectador reflexionar por sí mismo sobre el espacio y el tiempo.

\section{Conclusiones: el arte contemporáneo y la liberación femenina}

El cuerpo es un dispositivo que se presta a múltiples lecturas. Y mientras algunas interpretaciones parecen preservar la mirada masculina de la objetivización femenina, otras rompen con toda tradición, y nos hacen pensar en un cambio de paradigma con respecto al género y a las categorías. Nos parece que las autoras que ocupan nuestro análisis se inscriben en una perspectiva post-estructuralista del cuerpo. En este sentido, parecen pretender borrar las dicotomías, crear, a través de situaciones y discursos que ya existen, situaciones modificadas de lo que en principio se pensaría como un antagonismo sexual y genérico. La violencia del cuerpo, la mujer y su relación con la naturaleza, que la dibuja salvaje y con carácter, el cuerpo de mujer y su liberación cotidiana, constituyen algunas de las dimensiones buscadas. Si hay una línea definida que parecen compartir las artistas actuales y que heredan de las autoras vanguardistas, ésta sería la visión de control y de decisión con la que expresan su cuerpo. Así, por ejemplo, podemos recordar las performances de la artista Déborah de Robertis, quien posa desnuda en ocasiones durante actos públicos, por lo que ha sido acusada y juzgada de exhibicionista. La idea que la artista parece querer transmitir es aquella de posicionarse del lado del que mira y no del objeto, en este caso, el cuerpo mirado. Puesto que finalmente, toda imagen conlleva una percepción, y según la interpretación 
que le demos, el mensaje e incluso la representación misma varían. Si el cuerpo de mujer fuese pensado de forma distinta, no habría ningún problema en exhibirlo: "Mi performance no es ponerme desnuda. Lo que me interesa es invertir el punto de vista. Es como la representación de la ley, las relaciones de fuerza basculan desde la desnudez “.4

Ana Clavel destaca la imagen de las mujeres y su relación social como mercancías. El cuerpo de la mujer ha sido utilizado como producto de consumo por excelencia. La escritora y artista mexicana nos propone reflexionar acerca de ciertas figuras públicas que han decidido exhibir su cuerpo sin pudor, mostrando con orgullo su piel al mundo, y revelando una imagen social que no esconde su manera de comercializar con su imagen:

Críticas a favor y en contra, recuerdan el caso de la escritora, prostituta, activista social suiza Grisélidis Réal, cuyos controvertidos restos reposan a espaldas de la tumba del escritor Jorge Luis Borges en Ginebra, quien hizo de la prostitución un medio inicial de supervivencia para transformarlo después en un acto contestatario de la doble moral imperante. Qué lejos y cuán cerca el año de 1865 en que París se escandalizó por el desnudo de la prostituta Victorine Meurent, en el afamado cuadro de Manet, bautizado por Baudelaire como Olympia. (Clavel 2013: s/ n)

Para Vadillo, es quizá esta búsqueda de la artista actual por encontrar su propio lugar la cual la deja en una posición rota, herida, puesto que aún parece perdida por encontrar un imaginario propio que rompa definitivamente con la construcción masculina que la ha representado:

Quizás las artistas actuales están algo huérfanas y sean ellas las que tenga la misión de aportar nuevos referentes visuales a la sociedad con los que construir un imaginario propio. Por ello consideramos que, posiblemente, cuando lo femenino esté realmente asociado con nuevos significantes las artistas podrán vincular sus

\footnotetext{
${ }^{4}$ Interview avec Deborah De Robertis, ANONYME (2016). "Pour dénoncer la censure, l'artiste Deborah de Robertis se dénude une nouvelle fois dans un musée". Paris: France info.
} 
imágenes femeninas a un lugar propio, sin complejos y sin bagajes ajenos que haga de la mujer -al fin- la dueña de su propio discurso visual. (Vadillo 2009: 1401)

El problema que se nos plantea es que, si el cuerpo femenino es uno de los espacios privilegiados del arte, al representarlo como símbolo de identidad, éste sigue estando asociado a la feminidad como el rasgo esencial de la mujer misma. De ahí que la belleza femenina constituya el espacio público e íntimo fundamental que rodea a la mujer de nuestros días y esto esté lejos de cambiar. Por otro lado, la interacción del cuerpo con las políticas feministas es de suma importancia para conocer cómo cambian las estructuras sociales con respecto a la situación de la mujer. Como lo explica Mari Luz Esteban, se trata de hacer uso del cuerpo para referirnos a dominios más amplios que aquellos de la sexualidad, de la identidad y de la desigualdad de género. El cuerpo es un mecanismo que en nuestra sociedad mide y controla una amplia temática socioeconómica, la cual hace que nuestras conductas y prácticas permanezcan ligadas a un dominio que presenta una difícil definición y que abarca ámbitos muy controvertidos y diversos: "Ninguna cultura deja el cuerpo humano a su libre albedrío, pero en las sociedades capitalistas occidentales, dominadas por el consumo y el desarrollo de la tecnología, el cuerpo se ha convertido en un dispositivo preferente de regulación y control social, por un lado, y de denuncia y reivindicación, por otro" (Esteban 2011: 49).

Cristina Lucas es una artista andaluza contemporánea que reflexiona sobre las estructuras de poder y el falocentrismo a través de su obra. La forma en que Cristina plantea el tema de lo femenino se lleva a cabo de una manera sugestiva y sutil para pensar cómo la mujer se percibe y se gusta en nuestros días. Su colección, "Peinados" (2012), presenta algunas fotografías de la propia artista que llaman nuestra atención. 
"Peinado de mujer voladora" es una perspectiva de una fotografía de la artista que miramos de tal forma que nos invita a percibirla como si estuviera volando. Esta imagen nos hace pensar que el poder de la mujer se encuentra en la forma según la cual se la mira, y basta con girar nuestra mirada para percibir su fuerza. En otra fotografía vemos una mujer que juega con su pelo como un bigote que esconde su rostro, asemejándose a un hombre. Pero este juego de travestismo no deja de pensarla como mujer, lo femenino traspasa el disfraz del pelo y nos lleva a varios interrogantes: ¿pretendemos parecernos al hombre? ¿Somos una mezcla muy parecida? ¿Hay una identidad femenina?

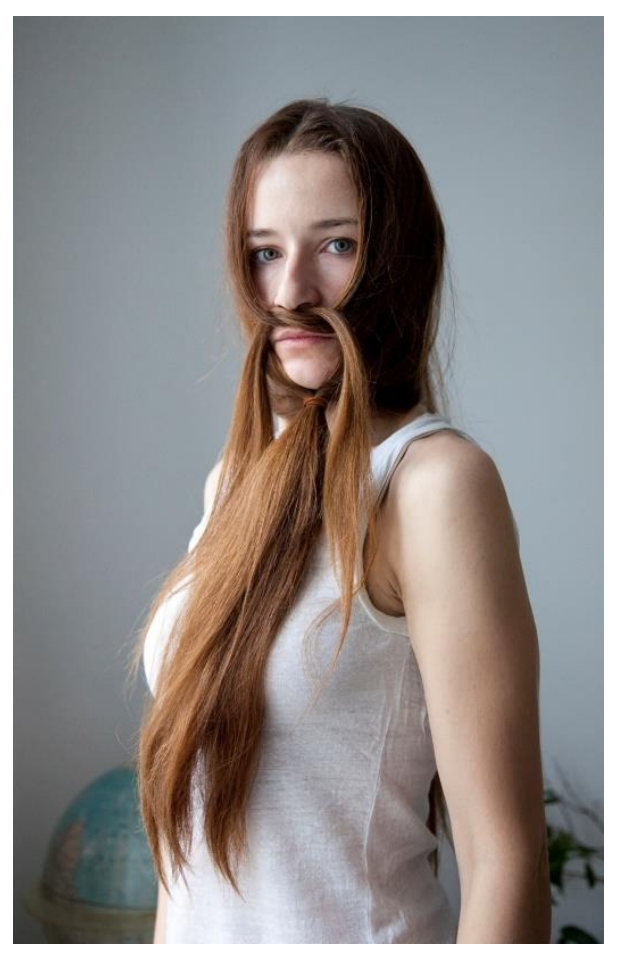

Gráfica 8. Lucas, Cristina. Peinados, 2012. 


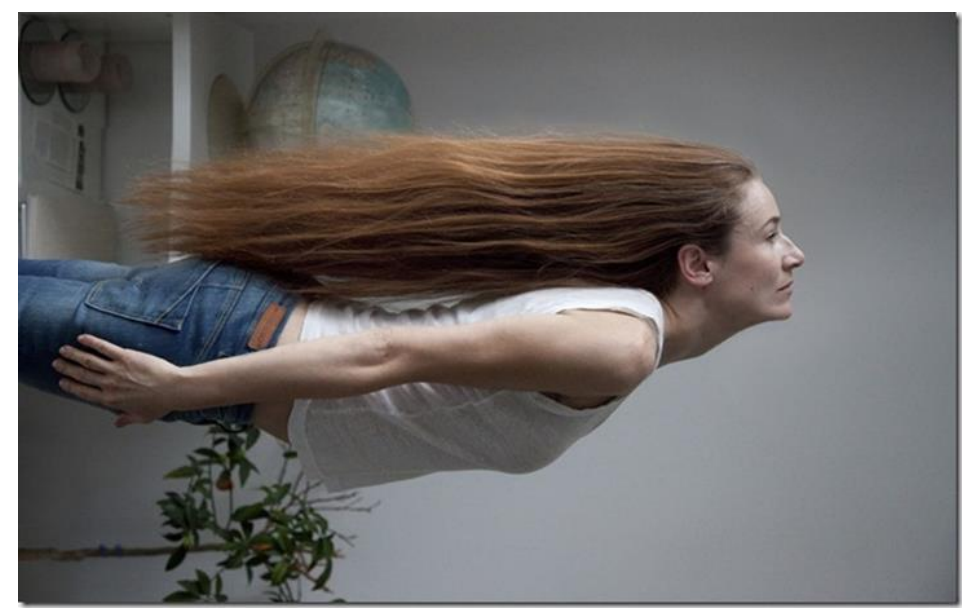

Gráfica 9. Lucas, Cristina. Peinado de mujer voladora, 2012.

Hoy, en el dominio de estudios culturales, el discurso sobre el cuerpo se inscribe a menudo en directa correlación con la filosofía de Foucault, inspirándose igualmente de los postulados de Judith Butler y de sus diferentes prácticas discursivas que nos esclarecen su dimensión histórica y política. Como lo señala el Diccionario de estudios culturales latinoamericanos: "El cuerpo es un escenario ambiguo que conlleva "tensiones, desplazamientos y ambivalencias que no se dejan reducir a una perspectiva "constructivista" ni a una aproximación "biológica", abriendo una zona de intercambios $\mathrm{y}$ de transformaciones que desbaratan a la vez todo esencialismo y todo relativismo cultural" (Szurmuk y Mckee, 2009: 67-71).

Para Esteban (2011), sería necesario una teoría y metodología sobre el cuerpo para poder indagar en las similitudes y diferencias como respeto al hombre y a la mujer. El dispositivo del cuerpo nos lleva a una serie de comportamientos y usos que implican nuestras emociones, actitudes y respuestas intelectuales. Entonces, podríamos pensar que se trataría de reeducar al cuerpo desde una forma similar entre hombres y mujeres, 
borrando todas esas actitudes antagónicas y la manera en que el cuerpo de mujer es percibido por el imaginario colectivo a través de la mirada sexual del hombre.

\section{Referencias bibliográficas}

Breton, André. 1935. Position politique du surréalisme. Paris: Ed. Le livre de Poche, 1991.

Butler, Judith. 1990. El género en disputa. El feminismo y la subversión de la identidad. México-Buenos Aires-Madrid, Paidós.

Clavel, Ana. 2013. A la sombra de los deseos en flor. www.AnaClavel.com

Carpio Jiménez, Lilia et al. 2014. "Naturaleza, Objeto y soporte en las manifestaciones artísticas de Ana Mendieta”. Departamento de Ciencias de la Comunicación. Ecuador: Universidad Técnica Particular de Loja

De Diego, Estrella. 2017. "La vida vanguardista de Maruja Mallo”. El País Semanal.

De Frutos, Rosalía. 2005. "Genio y figura de Maruja Mallo". Reseña del libro Maruja Mallo. La gran transgresora del 27, de Jose Luis Ferris. ojosdepapel.com

Esteban, Mari Luz. 2011. "Cuerpo y políticas feministas: El feminismo como cuerpo". Cuerpos políticos y agencia. Reflexiones feministas sobre cuerpo, trabajo y colonialidad. Granada Universidad de Granada.

Ferrer, Esther. Página oficial. Obras, exposiciones y performances. http://estherferrer.fr/es/

Ferris, José Luis. 2004. Maruja Mallo: la gran transgresora del 27. Barcelona: Temas de Hoy.

Freud, Sigmund. 1920-22. Más allá del principio de placer. http://colegioamerica.edu.

García Manso, Almudena. 2007. "Cyborgs, Mujeres y debates. El ciberfeminismo como Teoría”. Revista Castellano-Manchega de Ciencias Sociales. España.

García Villalba, Charo. 2011. "Las mujeres de la vanguardia española base del papel femenino en la postmodernidad". Espéculo. Revista de Estudios literarios. Madrid: Universidad Complutense de Madrid. 
Haraway, Donna. 1984. Manifiesto Ciborg. El sueño irónico de un lenguaje común para las mujeres en el circuito integrado. Traducción de Manuel Talens. https://xenero.webs.uvigo.es/profesorado/beatriz_suarez/ciborg.pdf

Llorca, Vicente. 1995. "Imágenes de la vanguardia: Maruja Mallo, Frida Khalo y Leonora Carrington". Revista Arte, Individuo y Sociedad. Madrid: Universidad Complutense Madrid.

Lucas, Cristina. Página oficial. Exposiciones y galería: http://juanadeaizpuru.es/artista/cristina-lucas/

Ludmer, Josefina. 1997. "Las tretas del débil". La sartén por el mango. Eds. Patricia González y Eliana Ortega. Colombia; Ediciones Huracán.

Morales, Grace. 2018. "El pop art y el feminismo en España”. Jot Down. Contemporary cultural magazine. https://www.jotdown.es/2018/03/pop-art-y-feminismo-enespana. [17/03/2019].

Neyens, Jean (2002). "Will Go Underground. Interview of Marcel Duchamp on the RTBF in 1965". Tout-fait. The Marcel Duchamp Studies Online Journal, 2 (4). https://www.toutfait.com/issues/volume2/issue_4/interviews/md_jean/md_jean.ht $\mathrm{ml}[17 / 03 / 2019]$.

Reyes Sepúlveda, Sofía. 2009. Frida Khalo. La inquietante extrañeza femenina en un arte en ruinas. Universidad de Chile: Facultad de filosofía y humanidades.

Rodríguez Barbero, Lara. 2015. "La percepción de la identidad a través de los feminismos en el arte: de Cindy Sherman al ciberfeminismo". Revista Clepsydra, 14: 25-36.

Speranza, Graciela. 2013. Fuera de campo. Anagrama: Buenos Aires.

Szurmuk M. et Mckee Irwin, R. Coord. 2009. Diccionario de estudios culturales latinoamericanos. Siglo veintiuno editores: México.

Vidal Claramonte, M. C. 2003. La magia de lo efímero. Representaciones de la mujer en el arte y la literatura actuales. Castelló de la Plana: Colec. Endes. Publicaciones de la universidad Jaume: España.

Vadillo Rodriguez, Marisa. 2009. "La deconstrucción del cuerpo femenino: el "No lugar" en el arte". Congreso Universitario Andaluz Investigación y Género: Sevilla. 